\title{
Sustainable Healthcare System in Nigeria: Vision, Strategies and Challenges.
}

\author{
Oyibocha, E.O. ${ }^{\mathrm{a}}$, Irinoye, O. ${ }^{\mathrm{b}}$, Sagua, E.O. ${ }^{\mathrm{c}}$, Ogungide - Essien, O.T. ${ }^{\mathrm{d}}$, \\ Edeki, J.E. ' \& Okome, O.L. ${ }^{\mathrm{f}}$. \\ ${ }^{I}$ School of Nursing, Warri, Delta State \\ ${ }^{2}$ Department of Nursing, Obafemi Awolowo University, Ile - Ife, Osun State \\ ${ }^{3}$ Faculty of Nursing, Medical - Surgical Department, Niger - Delta University, Bayelsa State \\ ${ }^{4}$ Family Planning Clinic, Department of Obstetrics and Gynaecology, College of Medicine, University of \\ Ibadan, Oyo State. \\ ${ }^{5}$ Primary Health Care Department, Ukwani Local Government Area, Obiaruku, Delta State 6School of Nursing, \\ Eku, Delta State
}

\begin{abstract}
Every nation's dream is for its government to achieve a sustainable improvement in the quality of life of its citizens. This can only be achieved through good governance and planned actions that detail the vision, mission, goals/objectives and strategies to be attained over a given period of time. Nigeria like other countries around the globe has not for once lacked any development plans. Unfortunately, with its current estimated population of 150 million and estimated total of 23,640 health facilities operated via a three - tiered governance structure, it is still ranked by World Health Organization at $187^{\text {th }}$ position in its health system among 191 member states. This article reviewed related relevant literature which revealed that, for more than two decades ago, African countries including Nigeria have been plunged into economic crisis which seriously affected a large portion of their populations and raised social and political tensions. To achieve sustainability, there is need for transformative plans and solutions that requires cooperation among industries and the government through delivery of minimum set of cost - effective interventions, packages and revitalization of the country's health system. Some of the major challenges of sustaining Nigeria healthcare system are: counterfeit and adulterated drugs, poor healthcare financing and sustainability, increased out-of-pocket expenditure, inadequate basic infrastructurelequipments/drugs and inequitable distribution, poor remuneration and other push factors, bribery and corruption and shortage of staff. This article concluded by recommending the following among others as the way forward; provision of a system of equitable distribution of healthcare facilities and drugs, implementation of cost - effective healthcare interventions plans, establishment of a functional and competent monitoring and evaluation systems.
\end{abstract}

Keywords: Sustainable, Health System, Vision, Strategies, Challenges, Nigeria.

\section{Introduction}

The absence of a plan whether short term, medium term or long term or in any society spells grim destiny. That is why no matter the size of a country, there is need for good governance with set of plan of actions with well defined vision, mission, goals and steps/approaches/strategies that are expected to be achieved at a given period of time.

Just like other countries in the world, Nigeria has not for once lacked development plans which even predate her independence on October $1^{\text {st }}, 1960$. Regrettably, Nigeria with an estimated population of over 150 million is still struggling with the provision of basic healthcare services (Health Reform Foundation of Nigeria [HERFON], 2006). It completely beats imagination that in spite of the enormous natural and human resources the country is blessed with, Nigeria is gradually drifting towards a "banana nation".

Obansa and Orimisan in 2013 opined that, for more than two decades now, most African countries has sloped steeply into an economic crisis which has seriously affected national development, impoverishing sections of their populations and whipping up social and political tensions intermixed with religious intolerance. The crisis has led to external forces interference, notably multilateral and bilateral donors, as these nations attempt to set out their plans for sustainable development. Globally however, every nation's aim is for its government to achieve a sustainable improvement in the quality of life of its citizens. To achieve sustainability therefore, transformative solutions that require cooperation among industry sectors and the government are needed.

According to the World Economic Forum Report (2013), for the past two centuries, health care expenditure outstrips Gross Domestic Product (GDP) growth for the Organization for Economic Co-operation and Development (OECD) countries. The total health expenditure has risen and at an average annual rate of $2 \%$. Some estimates suggested that by 2040 total expenditure could rise by another $50-100 \%$. This therefore 
Sustainable Healthcare System in Nigeria: Vision, Strategies and Challenges.

calls for a critical thinking by the health system leaders, directors and stakeholders regarding the future, and assurance of high quality healthcare services delivery that is fully accessible, affordable, sustainable, properly managed and controlled. This is non - negotiable because it is only a healthy society that will ensure a sustainable national development and subsequently place the nation among the comity of nations around the globe.

\section{Concept Of Health Care System}

Good health is one of the fundamental human rights everybody is entitled to enjoy. And the onus rests on the healthcare system to provide health services at the three tiers of the government (federal, state and local government). A health system can then be said to be an organization of people, institutions, and resources that deliver health care services to meet the health needs of target populations. Health system planning then should be distributed among market participants, governments, trade unions, charities, religious, or other coordinated bodies to deliver planned health care services targeted to the populations (Frenk, 2010).

World Health Organization [WHO] (2000) identified three basic goals of a healthcare system which include:

1. Good health (improvement and protection of the health of the populace)

2. Fair financial contribution (receiving the services paid for)

3. Responsiveness of the healthcare providers (living up to the people's expectation)

Achievement of these goals is dependent on how the healthcare systems carryout the following functions:

a. Rendering of efficient health services

b. Resources generation such as healthcare financing (raising, pooling and allocating)

c. Health investment such as material resources

d. Stewardship such as human resources.

Other dimensions for the evaluation of health systems include quality, efficiency, acceptability, and equity. They have also been described in the United States as "the five C's": Cost, Coverage, Consistency, Complexity, and Chronic Illness (Brody, 2007).

\section{Situation Analysis}

The Federal Republic of Nigeria has an estimated population of 150 millions of which $49 \%$ are female and $51 \%$ male. The country operates a three-tiered governance structure - a Federal Government, 36 semiautonomous State Governments grouped into six geopolitical zones, the Federal Capital Territory and 774 Local Governments, with wide regional, socio-cultural, economic and geographical diversities existing across the country (National Planning Commission [NPC], 2008).

States and LGAs revenue, contributing to funding for health care are largely dependent on allocations from the federal government as their internally generated revenues are usually low. Nigeria has enjoyed a period of economic growth with the Gross Domestic Product (GDP) rising from 2.5\% in the 1990's to 6\% during the period $2004-2007$ with average annual inflation rates falling from $20.6 \%$ to $11.6 \%$ over the same period. Although in recent times, the global economic recession has adversely affected the country's economy with a GDP of over \$181 billion (Central Bank of Nigeria [CBN] (2008). It is also estimated that more than half of Nigerians (54.4\% or 76 million) live in poverty with $70.8 \%$ of this living below the poverty line of less than $\$ 1$ per day. Poverty is found to be predominant in the rural areas than urban areas and deepens from the southern to the northern part of the country (United Nations Development Program [UNDP], 2007).

In Nigeria, life expectancy at birth as at 2005 was $46.6 \%$ compared to $77.8 \%$ in developed countries (UNDP, 2007). Still in 2005, maternal mortality rate was 110 per 100,000 live births (UNDP, 2007). In 2003, neonatal mortality rate was 48 per 1,000 live births (National Bureau of Statistics [NBS], 2008). Infant mortality rate in 2005 was 133 per 1,000 live births as against 41 per 1,000 live births in developed nations in 1970 and 9 per 1,000 live births in 2005 (UNDP, 2007). In 2003, under-five mortality rate was 257 per 1,000 live births as compared with 54 per 1,000 live births in developed countries in 1970 and 11 per 100,000 live births in 2005 (UNDP, 2007). Again, 11,854 deaths from notifiable diseases were reported in Nigeria in 2006 and 15,680 in 2007. HIV/syphilis sero-prevalence rate in 2005 in Nigeria was $11.4 \%$ and just $1 \%$ in developed countries (NBS, 2007b).

All these happenings in Nigeria are largely due to inadequate immunization coverage, unawareness of the public, poor nutrition, unsafe water and poor sanitation exercises (Eneh, 2011). Eneh simply captured what is really prevalent in the rural area of the country, which is occupied by about $70 \%$ of the country's population. Corroborating Eneh's submission, UNDP (2007) affirmed that, only $48 \%$ of Nigerians had access to improved water and 44\% good sanitation in 2004. 


\section{Health Care System In Nigeria}

Nigeria as a nation operates a pluralistic health care delivery system (orthodox and traditional health care delivery systems). Orthodox health care services are provided by private and public sectors. However, the provision of health care in the country remains the functions of the three tiers of government: the federal, state, and local government. The primary health care system is managed by the 774 local government areas (LGAs), with support from their respective state ministries of health as well as private medical practitioners. The secondary health care system is managed by the ministry of health at the state level. The tertiary primary health care is provided by teaching hospitals and specialist hospitals. The secondary and tertiary levels, also work with voluntary and nongovernmental organizations, as well as private practitioners (Adeyemo, 2005).

In 2005, the Federal Ministry of Health (FMoH) estimated a total of 23,640 health facilities in Nigeria of which $85.8 \%$ are primary health care facilities, $14 \%$ secondary and $0.2 \%$ tertiary. $38 \%$ of these facilities are owned by the private sector, which provides $60 \%$ of health care in the country. In spite of the availability of this huge number of healthcare facilities and advancement in technology the health sector in Nigeria has witnessed various turbulent with its attended negative effects. As affirmed by Obansa and Orimisan (2013), with the country's teeming population now estimated at over 150million, it is still struggling with the provision of basic health services. And according to HERFON (2006), health facilities (health centers, personnel, and medical equipments) are inadequate in the country, particularly in rural areas. This of course clearly explains the high mortality rate in children, maternal and even adults over the years.

Nearly fifteen (15) percent of Nigerian children do not survive to their fifth birthday. The major causes are malnutrition that accounts for fifty-two (52) percent of the deaths, malaria thirty (30) percent and diarrhea twenty (20) percent (Federal Ministry of Health $[\mathrm{FMoH}], 2004)$. Maternal mortality reported as being is extremely high. In 2008, between 3million and 3.5million people were estimated to be living with HIV/AIDS. Nigeria has the fourth highest number of TB cases in the world, with a 2004 estimate of 293 new cases per 100,000 population and 546 per 100,000 total cases (Obansa \& Orimisan, 2013).

Another key issue linked with health indicators in Africa is poverty and in Nigeria, the incidence of poverty is widespread. Between 2003 - 2004, a household survey was conducted by the government and results revealed that 54.4 percent of the Nigeria population is poor, with a higher poverty rate of 63.3 percent in rural areas. Over half of the population live below the poverty line, on less than $\$ 1$ a day and so cannot afford the high cost of health care (HERFON, 2006).

Obansa and Orimisan (2013) identified the following among others as the factors affecting the overall performance of the Nigerian healthcare system:

- Inadequate health facilities/structure

- shortage of essential drugs and supplies

- Inadequate supervision of the healthcare system

- Poor human resources, management, remuneration and motivation

- Lack of fair and sustainable health care financing with very low per capita health spending

- Unequal economic and political relations

- The neo-liberal economic policies of the Nigerian state and corruption

- High out-of-pocket expenditure in health by citizens

- Absence of community-based integrated system for disease prevention, surveillance and treatment

It became very necessary to brainstorm and come up with plans and strategies that will checkmate the aforementioned factors that militate against effective health care system in the country. Obansa and Osrimisan (2013), highlighted some strategies among others which will help to tackle the health sector challenges in the country as follow:

- improved access to primary healthcare

- Strategic and purposeful leadership in health delivery services

- Increase fund to manage the health sector

\section{Sustainable Health Care System In Nigeria}

In 2000 according to World Health Organization (WHO), Nigeria's overall health system performance was ranked $187^{\text {th }}$ position among 191 member States. Primary Health Care (PHC), which forms the bedrock of the national health system, remains comatose due to gross under funding, mismanagement, corrupt practices and lack of capacity at the local government level. 
Sustainable Healthcare System in Nigeria: Vision, Strategies and Challenges.

\section{Visions}

In the Ward Minimum Health Care Package [WMHCP] (2001); Global Health Initiative [GHI] (2010 2015) and the National Strategic Health Development Plan [NSHDP] $(2010$ - 2015) the under listed visions to sustain the Nigeria health care system were projected:

- Attainment of Health For All Nigerians through the Primary Health Care

- Strengthening the national health system through the primary health care (PHC) approach

- Increasing economic productivity

- Sustaining national development and gender equality

- Improving access to commodities

- Strengthening partnerships and research for health as the building blocks of a functional health system

\section{(1). Ward Minimum Health Care Package (Wmhep)}

\section{Strategies}

According to NPHCDA (2012), WMHCP is a reviewed package of the Minimum District Health Care Package for Nigeria (MDHCPN) for the acceleration of Health For All (HFA) through Primary Health Care (PHC). MDHCPN was born in August, 1994 out of the $16^{\text {th }}$ WHO Regional Meeting in Yaoundẽ, Cameroon in February, 1994. The package consisted of four components which include:

i. Safe motherhood [maternal and new born] (antenatal, intranatal, postnatal and family planning)

ii. Child Survival (Integrated Management of Childhood Illness [IMCI], neonatal care and routine immunization)

iii. Control of Communicable diseases of public health importance (malaria, tuberculosis, human immune virus/acquired immune deficiency syndrome [HIV/AIDS])

iv. Health Information, Education and Communication

The reviewed package WMHCP was in line with the introduction of the Ward Health System (WHS) in 2001 and two other components were incorporated thereby increasing the components to six. The additional components are:

a. Nutrition

b. Control of Non Communicable diseases

Grass root level is the target of the package via the delivery of a minimum set of interventions that are costeffective and known to promote health and reduce morbidity and mortality from common diseases.

\section{Components Of Wmhep}

i. Safe motherhood [maternal and new born] (antenatal, intranatal, postnatal and family planning): - In Nigeria, the estimated maternal mortality rate is 545 per 100,000 live births with wide regional disparity (National Demographic and Health Survey [NDHS], 2008). An estimated $40 \%$ of pregnant women suffer from pregnancy related problems, while $15-20 \%$ of women suffer from debilitating conditions like pelvic inflammatory diseases (PID), vesico-vaginal fistula and ruptured uterus due to obstructed labour (Reproductive Health Situation of Nigeria: ENHANCE Project, 2005). In addition NDHS (2008) noted that, about $57.7 \%$ of pregnant women received antenatal care from healthcare professional and $36.3 \%$ did not receive any form of antenatal care at all. Only $38.9 \%$ had their babies delivered at a health facility attended by a skilled professional and $65 \%$ delivered at home attended by unskilled persons in an unclean condition. Again NDHS (2008) gave $5.7 \%$ as Total Fertility Rate (TFR) with contraceptive prevalence rate of $14.6 \%$ among married women of age $14-49$ years.

\section{Ward Minimum Health Package for Safe motherhood:}

The package consists of the establishment of one Basic Essential Obstetric Care Center (BEOC) in each ward. These centers should be:

- Adequately be staffed with at least four (4) skilled midwives or nurse/midwife for 24 hours coverage.

- Provided with all basic obstetric equipments

- Provided with adequate stock of Non-Pneumatic Anti-Shock Garment

- Provided with basic obstetric drugs; iron-folate, oxytocin, misoprostol, sedatives and antibiotics

- Provided with transportation facilities for referral

ii. Child Survival (Integrated Management of Childhood Illness [IMCI], neonatal care and routine immunization): - According to NDHS (2008), in Nigeria, neonatal mortality rate is 40 per 1000 live births, infant mortality rate is 75 per 1000 live births and under five years is 157 per 1000 live births. $37 \%$ of the neonatal deaths were due to infection, while preterm birth and asphyxia accounted for $49 \%$ deaths. $78 \%$ of death of under five deaths were secondary to malaria, acute respiratory infections especially pneumonia, diarrhea, malnutrition and vaccine preventable diseases particularly measles. 


\section{Ward Minimum Package for Child Survival:}

- Neonatal care - This involves clean and skillful delivery procedures, resuscitation of the new born, proper hand washing, routine birth care, early breast feeding (30 minutes following delivery), and exclusive breast feeding. In addition, Kangaroo Mother Care Method for low birth weight infants, management of neonatal infections and provision of referral and outreach services.

- $\quad$ Routine immunization - This involves the vaccination of infants and children to protect them from the killer diseases such as Tuberculosis (BGC vaccine); Poliomyelitis (polio vaccine); Yellow Fever (yellow fever vaccine); and Diphthera, Tetanus, Whooping Cough, Hepatitis B and Haemophilia influenza type B (pentavalent vaccine) (NPHCDA, 2012).

- $\quad$ IMCI - This strategy aims at reducing childhood morbidity and mortality rates as well as promotion of healthy growth and development of under five children utilizing cost-effective interventions. IMCI targets five major diseases: malaria; measles; acute respiratory infections particularly pneumonia; diarrhea and malnutrition. The strategies ensures accurate identification and treatment of childhood diseases, strengthening of preventive services like use of insecticide treated nets (ITN), increasing immunization coverage, prompt referral of severe cases among other services (NPHCDA, 2012).

iii. Control of Communicable diseases: - Nigeria has a high burden of communicable diseases. These diseases can be classified as (i) diseases targeted for eradication such as Leprosy, Onchocerciasis, Poliomyelitis (b) notifiable diseases such as Meningitis, Cholera, Yellow Fever (c) diseases of health importance such as malaria, STI/HIV/AIDS, tuberculosis (NPHCDA, 2012).

\section{Ward Minimum Package for Control Malaria}

- Availability of insecticide treated nets (ITNs) for all pregnant women and children under five years.

- Provision and use of Arteminsinin based Combination Therapy (ACT) for treatment of uncomplicated malaria.

- Institutionalizing effective case management of malaria in the community and all health facilities.

- Provision of Sulphadoxine-Pyrimethamine for intermittent prevention treatment in pregnant women. (NPHCDA, 2012).

\section{Ward Minimum Package for Control Tuberculosis}

- Provision of basic laboratory infrastructure and equipment in all ward health centers for case identification of tuberculosis

- Ensure the availability of drugs and infrastructure for Direct Observation Treatment Short Course (DOTS) such as Rifampicin, Streptomycin, Ethambutol etc for identified cases.

(NPHCDA, 2012).

\section{Ward Minimum Package for STI/HIV/AIDS}

- Availability of Voluntary Counseling and Testing (VCT) services such as trained counselors, conductive infrastructure and Rapid Test kits for HIV in all wards.

- Provision of condoms and establishment of logistic mechanisms for their distribution

- Treatment of opportunistic infections

- Routine implementation of Information, Education and Communication (IEC) and Behavioral Change Communication (BCC) activities. (NPHCDA, 2012).

iv. Health Information, Education and Communication: - In 2008, NDHS indicated that approximately $46.1 \%$ females and $30.5 \%$ males respectively did not receive any form of education. In pursuit of achieving higher levels of community mobilization, government is implementing health education programs on the different areas of primary health care and they will provide information on health promotion, disease prevention at community and individual levels. A deliberate effort to improve collaboration and participation should be implemented.

\section{Ward Minimum Package for Health Information, Education and Communication}

- At least two health workers and two members of the community per ward trained as health educators

- Every facility to have relevant IEC/BCC materials with cultural acceptable language and graphics

- A logistic vehicle or motor cycle with public address system to be available at local government levels for the purpose of health education.

(NPHCDA, 2012)

v. Nutrition: - The nutritional status of the vulnerable groups, notably women and children in Nigeria is poor. Malnutrition in children increases the likelihood of mortality from a number of complications. Vitamin A deficiency is associated with night blindness; anemia due to iron, folate and vitamin deficiency could increase risk of premature delivery and low birth weight (NPHCDA, 2012).

\section{Ward Minimum Package for Nutrition}

- Health and nutritional educational materials

- Provision of equipment for food demonstration in all wards 
- Establishment of community based growth monitoring in all communities by trained volunteers, with appropriate equipment such as Child Health Cards and health facility based growth monitoring

- Implementation of food security program at household and community levels (NPHCDA, 2012).

v. Control of Non Communicable diseases: - Non - Communicable Diseases (NCDs) has emerged as an important public health problem in Nigeria due to progressive urbanization, industrialization and increased consumption of processed food. The onset of such diseases is usually very slow, progresses over time to a chronic state. Examples of NCDs are coronary heart disease, cancers, occupational related diseases like asbestosis and silicosis etc. The prevention of NCDs requires individuals to take health actions without any apparent health problem (NPHCDA, 2012).

\section{Ward Minimum Package for Non - Communicable diseases prevention}

- $\quad$ Phased capacity building of health workers for prevention and control of NCDs in all facilities

- Availability and display of IEC materials on NCDs in all facilities

- Provision of basic equipments for screening and early diagnosis of NCDs such as urine testing kits, weighing scales, hyetometer, sphygmomanometer etc

- A functional two way referral system to ensure prompt referral of diagnosed cases and community based management

(NPHCDA, 2012).

(2). The National Strategic Health Development Plan [Nshdp] (2010 - 2015)

NSHDP is another agency that actively provided financial as well as technical support to Nigeria in respect to healthcare system is the United Nations Population Fund (UNFPA).

\section{Vision}

"To reduce the morbidity and mortality rates due to communicable diseases to the barest minimum; reverse the increasing prevalence of non-communicable diseases; meet global targets on the elimination and eradication of diseases; and significantly increase the life expectancy and quality of life of Nigerians".

\section{Mission Statement}

"To develop and implement appropriate policies and programs as well as undertake other necessary actions that will strengthen the National Health System to be able to deliver effective, quality and affordable health".

UNFPA served on the five-member coordination team that developed the conceptual framework for the country health sector plan - The National Strategic Health Development Plan (NSHDP). Fundamentally, NSHDP admonishes the leadership of the Federal Government of Nigeria to embark on a very complex but inclusive process of reform, with significant challenges to address moving forward but with the ultimate vision of a strengthened, coordinated, re-invigorated and sustainable health care delivery system.

The development of the NSHDP was through an extensive consultation process at all levels involving the States, Local Government, Civil Society and Development Partners led by the Federal Ministry of Health $(\mathrm{FMoH})$. The process included undertaking background studies to assess the health system and constraints to scaling up the development of a framework to guide the elaboration of the NSHDP, which was adopted in July, 2009. Also, developing and costing the LGAs, States and Federal Health Plan, which subsequently were collated and harmonized into the NSHDP. NSHDP was however approved by the National Council on Health in March 2010, the Federal Executive Council in November 2010 and formally launched in December 2010. The NSHDP therefore was developed in accordance with extant national health policies and legislation, and international declarations and goals to which Nigeria is a signatory to, namely; MDGs, Ouagadougou Declaration on PHC and the Paris Declaration on Aid Effectiveness.

By integrating the plans prepared by the 36 States of the Federation and the Federal Capital Territory, the NSHDP is expected to provide an overarching framework for sustained health development in Nigeria over the period 2010-2015. This was subsequently confirmed through the Partnership Declaration on Mutual Accountability in which the President, Vice President, 36 Executive Governors and the FCT Minister, of the Federal Republic of Nigeria all committed to the 'results-oriented National Strategic Health Development Plan and the State Strategic Health Development Plans as part of the continued implementation of the health sector component of Vision 20:2020'.

The development of the NSHDP have positively led to the strengthening of capacities both at the federal and state levels which now address areas such as strategic planning and budgeting processes, priority setting, costing, policy dialogue and harmonization and alignment.

Key issues to be addressed by the NSHDP are as follows:

$a$. The weakened Nigerian health system 
Sustainable Healthcare System in Nigeria: Vision, Strategies and Challenges.

b. Organization and management of difficulties that affect the entire health system

c. Lack of clarity in the division of responsibilities across different levels of government

$d$. The weak linkage across the different levels of government and stakeholders as regards health issues

e. Effective decentralization

$f$. Inadequate governance and accountability at all levels of the health system

g. Dynamic private sector offering opportunity to fill part of the gap left by a weak PHC system

\section{(3). Nigeria Global Health Initiative Strategy (2010 - 2015)}

As presented by the United States Government Interagency Team (2011), the Global Health Initiative (GHI) is a strategy designed to improve the efficacy and impact of all United States international health programs through closer inter-agency, bilateral, and multi-lateral coordination. In Nigeria, GHI is positioned to build upon the priorities of the Government and the Nigerian private sector.

\section{THE US GOVERNMENT (USG) VISION FOR GHI IN NIGERIA}

The USG vision for GHI in Nigeria is to use existing relationships to build a health care delivery system which will meet the needs of the country's population.

\section{GLOBAL HEALTH INITIATIVE (GHI)}

The launch of the GHI coincides with the development of the country's National Strategic Health Development Plan (NSHDP) 2010 - 2015. NSHDP provides a framework with which other existing policies, strategies, programs, and partnerships are to be aligned.

The USG Inter-Agency Team for GHI in Nigeria is comprised of the U.S. Agency for International Development (USAID); the U.S. Centers for Disease Control and Prevention (CDC); the Department of State, represented by the Coordinator of the President's Emergency Plan for AIDS Relief (PEPFAR); Environment, Science, Technology, and Health Officer (ESTH); and the Walter Reed Program - Nigeria (DOD WRP-N) of the U.S. Department of Defense. The USG Team reports to the Ambassador who in turn coordinates with the Executive Director for GHI in the U.S. Department of State.

\section{OBJECTIVES OF GHI}

The objectives of GHI are to:

- $\quad$ reduce maternal, neonatal and child mortality and morbidity

- decrease unintended pregnancies

- reduce the incidence of communicable diseases (HIV, TB, and malaria).

\section{STRATEGIES OF GHI}

1. Improved Human Resources For Health (Hrh)

The USG through GHI intends to pursue a coordinated set of activities designed to further HRH strategic interventions outlined in the NSHDP by:

- Improving human resource planning and management

- Increasing the quality of professional training programs

- $\quad$ Promoting implementation of the HRH policy

- Increasing the capacity of professional and technical associations/ regulatory bodies

2. Improved Delivery Of Highest Impact Interventions, Particularly At The Phc Levels

The USG will engage in a comprehensive and rigorous program in full support of the government of Nigeria (GON)'s own plans to revitalize PHC through implementation of a minimum integrated package of care by:

- Strengthening health infrastructure with a special focus on PHCCs and referral facilities

- Increasing availability of essential drugs, health commodities, and supplies at all facility levels

- Strengthening integrated data collection, analysis and use

- Increasing quality and availability of private sector services

- Strengthening community-based health promotion, service provision and linkages between communities and facilities

- $\quad$ Strengthening capacity in epidemiology, disease surveillance, and response

3. Strengthened Leadership, Management, Governance And Accountability

Success in this area will be achieved through the following:

- Increase political commitment and capacity at national, state, LGA, ward and community levels, and in the private sector, in order to implement the NSHDP 
Sustainable Healthcare System in Nigeria: Vision, Strategies and Challenges.

- Improve coordination and linkages between levels of the health system

- Improve resource allocation and expenditures

- Strengthen organizations, mechanisms and systems for transparency, accountability and responsiveness

- $\quad$ Enhance the policy environment

\section{Monitoring, Evaluation And Learning}

The USG will support many measurement activities to produce dependable data to judge results in collaboration with the GON, private sector and other DPs/donors.

The highly-respected NDHS 2008 will continue to serve as the primary tool for collecting data on impact-level health indicators including maternal, neonatal, under-five health and HIV/AIDS status.

\section{Communications And Management Plans}

The GHI is guided by the U.S. Ambassador. He has the responsibility to ensure that the USG implements GHI in accordance with GHI principles. And as part of its public advocacy efforts, the U.S. Embassy's Public Affairs Office will support the USG GHI Inter-Agency Team with outreach on USG health programs in Nigeria through the media as deemed necessary and appropriate by the Ambassador. In this vain, the power mass media must be fully exploited the to communicate health plans and strategies to the people, especially those in the rural settlements.

\section{Linking High-Level Goals To Programmes}

The USG will address social, economic, legal and cultural determinants of health through a multisectoral approach that utilizes multiple community-based programmatic approaches such as community mobilization, advocacy, and engagement of community leaders/role models to improve health for women and girls. The goal of these efforts is to increase the participation of healthy girls and women in all stages of programs.

\section{Encourage Country Ownership And Invest In Country-Led Plans}

The USG participated at the invitation of the GON in the development of the NSHDP 2010-2015. In collaboration with other DPs/donors, the USG has been asked by the GON to support its attempts to implement the programs and achieve targets in the NSHDP's Results Framework.

\section{Promote Research And Innovation}

Research and evaluation provides the evidence base for all health decisions and as such is central to GHI. The USG will continue to promote quality data collection practices, encourage evidence-based decisionmaking and strive for innovation through clinical, therapeutic and operational research.

\section{Revitalization Of The Nigerian Health System}

According to NSHDP (2010 - 2015) and the Nigeria Annual Health Sector Report (2010), the NSHDP framework was developed to serve as a guide to Federal, State and LGAs in the selection of evidenced-based priority interventions that would contribute to achieving the desired health outcomes for Nigerians. Eight evidenced-based priority areas were identified to improve the performance of the health sector, through a holistic approach at federal, state and LGA levels. These include:

PRIORITY AREA 1: LEADERSHIP AND GOVERNANCE FOR HEALTH: This seeks to streamline and empower the Ministries of Health at the Federal, State and LGA levels. It recommends interventions to enhance mutual accountability and transparency in the use of health development resources, particularly through resultsbased management approaches.

PRIORITY AREA 2: HEALTH SERVICE DELIVERY: Health care services are geared towards the provision of comprehensive healthcare services to the care recipients through the primary, secondary and tertiary levels. This would of necessity require interventions that transform the way the health care system is resourced, organized, managed and services delivered.

PRIORITY AREA 3: HUMAN RESOURCES FOR HEALTH: Human Resources for Health (HRH) comprise trained health personnel in the public and private sector - doctors, nurses/midwives, pharmacists, community health workers etc. It also includes untrained informal health workers e.g. traditional birth attendants and volunteers, who play complementary roles in health care service delivery. The intervention here is to get the right number of health personnel, in the right place, at the right time doing the right job, at the right pay and motivated to stay on, based on the right incentives.

PRIORITY AREA 4: HEALTH FINANCING: Health care costs (services and transportation costs), lack of knowledge/unawareness, negative health seeking behaviors are some of the factors that lead to poor utilisation 
Sustainable Healthcare System in Nigeria: Vision, Strategies and Challenges.

of modern health services which eventually results in poor health outcomes for majority of the citizens of Nigeria. The intervention of allocating enough budgets for health is required in this regard.

PRIORITY AREA 5: NATIONAL HEALTH INFORMATION SYSTEM: Many a times, health data is either incomplete or not available, thus making it very difficult to know if health interventions are making any impact. What is needed is to make available structures on ground functional by providing the appropriate resources in terms of materials, money and manpower.

PRIORITY AREA 6: COMMUNITY PARTICIPATION AND OWNERSHIP: Inadequate community participation has resulted in inappropriate sitting of PHC facilities in inaccessible or unacceptable locations. The intervention required is for communities to be actively engaged in needs identification, planning and implementation of health programs which will give the people a sense of belonging. Also, they should be empowered to improve their health situations through their active participation/involvement.

PRIORITY AREA 7: PARTNERSHIPS FOR HEALTH: Health is a multidimensional issue and government alone cannot meet all the health needs of the people in Nigeria. The intervention needed is partnership with the private sector, non-governmental organizations, development partners (donors), social and economic sectors so as to deliver health services that can meet the needs of the population on a sustainable basis.

PRIORITY AREA 8: RESEARCH FOR HEALTH: At the State level, policy makers and decision takers need to know how well their health programs are being received by the people. In other words, there is need for feedback and acting on such feedbacks to improve on services rendered. The intervention here is for every State Ministry of Health department of Planning, Research and Statistics to take charge of this.

\section{Challenges Of Sustainable Healthcare System In Nigeria}

Some of the major factors that affect the sustainability of the health system and invariably, the economic growth and development in Nigeria include the following:

1) Counterfeit and adulterated drugs - For many years Nigeria was plagued by counterfeit and substandard drugs. WHO ( 2006), reported 70\% of substandard drugs in Nigeria and the National Agency for Food and Drug Administration and Control (NAFDAC) estimated 41\% of fake drugs (Yankus, 2006; Akunyili, 2007). These counterfeit drugs have led to the loss of several lives and heavy cost in economic terms. According to Reef (2008) a total of 109 children in 1990 were reported dead after the administration of fake paracetamol.

2) Poor health care financing and sustainability - In Nigeria, the federal government health spending increased from the equivalent of US\$141 million in 1998 to the equivalent of US\$228 million in 2003. State spending on health estimate was about US\$420 million or US\$3.50 per capita in 2003. Majority of the spending by both the federal and state governments is concentrated on the teaching hospitals, federal medical centres and state owned hospitals respectively. (World Bank CRS, Nigeria, 2005). Once there is problem with the budgeting system in a country where little resources is allocated to the health care system, there is bound to be an increased out-of-pocket expenditure by the consumers of the services. To ensure sustainability of the system, the financing system of the country according to Obansa and Orimisan (2013) should be able to protect its populace from exuberant health services expenses when they are ill and encourage the service personnel to offer effective preventive and curative services.

3) Increased out-of-pocket expenditure - Payments made for health services at the time of illness are referred to as out-of-pocket expenditures. These payments are for consultation, treatments, transportation to the facilities, laboratory charges and/or hospitalization charges (which is more costly). When communities are denied access to essential drugs, facilities and necessary equipments and personnel due to uneven distribution and allocation of resources, sick members have no option but to seek for help in private sectors. Payments for consultation, treatments and/or hospitalization (which is more costly) will however constitute a burden for the sick person and his/her entire household. In 2004, the Nigeria Living Standard Survey (NLSS) surveyed 19,159 samples of households in the country. Data generated revealed that, the estimated average annual per capita outof-pocket spending on health is $\# 2,999.00$ (Nigeria naira), equivalent to about $\$ 22.50$ (US dollars). This then accounts for $8.7 \%$ of household expenditures on health which includes expenditure on outpatient care, transportation to healthcare facilities and treatment/medication (Obansa \& Orimisan, 2013). Furthermore, it has been found that one of the largest proportions of total health expenditure in the country is private healthcare spending. Of total health expenditures, government covers $25.5 \%$, while private expenditure comprises the remaining $74.5 \%$ of which $91 \%$ of the private expenditures are out-of-pocket (WHO, 2006). Again in the same 2004, out-of-pocket health expenditure in private health sector was nearly $70 \%$ of total health expenditure. Government total health expenditures were equal to $30.4 \%$ (WHO; 2004). In other words, about $4 \%$ of households spend more than half of their total expenditures on healthcare (Federal Republic of Nigeria[FRN], 2004).

4) Inadequate basic infrastructure and equipments - The heart of the Nigerian health policy is the provision of universal health services to all citizens. Section 17(3)(d) of the Constitution states that "The State shall direct its policy toward ensuring that there are adequate medical and health facilities for all persons". 
Sustainable Healthcare System in Nigeria: Vision, Strategies and Challenges.

Again in 1999, the Nigeria government during the last days of the military regime headed by president Olusegun Obasanjo established the National Health Insurance Scheme (NHIS) by Act 35 of the constitution. The objectives of the scheme include; the provision of access to good health care services; protection of families from the financial hardship of huge medical bills; and ensuring equitable distribution of health facilities throughout the country (Akinnaso, 2014). Availability of basic infrastructure and equipments at the different levels of health facilities enhance good health services provision. Inequitable supply and distribution of available resources, unavailable buildings, electricity, equipments and drugs have been found to be common in the country (Obansa \& Orimisan, 2013). They further noted that in some communities, the habitants have "to travel over $5 \mathrm{~km}$ to access health care because sitting of structures is often based on political expediency rather than perceived need" (p.223). In another development, WHO Country Cooperation Strategy: Federal Republic of Nigeria 2002-2007, showed that, the proportion of households residing within 10 kilometers of a health centre, clinic or hospital is $88 \%$ in the southwest, $87 \%$ in the southeast, $82 \%$ in the central, $73 \%$ in the northeast and $67 \%$ in the northwest regions.

5) Inadequate supply and inequitable distribution of essential drugs - Provision of drugs that are evenly distributed is essential for the essential for the delivery of effective health care. In Nigeria, drug supply especially in the primary health centres (PHCs) is inadequate. FMoH in 2001 conducted a survey and reported that, out of the available 674 PHCs in 202 local governments, $46 \%$ had less than half of the essential drugs and $54 \%$ had experienced out-of-stock in the preceding three months. Again in 2002, FMoH conducted another survey and found out that, $64 \%$ of the PHCs have not been supplied any drug from the government since the year 2000. Absence of these essential drugs including vaccines for curative and preventive services, needed personnel, facilities and equipments in the healthcare system would mean pushing the affected populace to sought alternative care to promote their health and well-being. Some however resort to private sectors, unqualified health personnel and even traditional healers. The poor drug supply and distribution system has led to problems of drug resistance such as resistance to anti-malaria drugs (HERFON, 2006 \& FMoH, 2004),

6) Unawareness and participation in healthcare services - It has been observed that most consumers of healthcare services are unaware of available healthcare services and their rights regarding health service delivery. This can be attributed to the lack of "a bill of rights for consumers (claim holders) and providers (duty bearers)" (Obansa \& Orimisan, 2013.p.223). Sensitization of the various communities to create more awareness and encourage community mobilization and participation in issues concerning their health is required.

7) Poor remuneration, compensation and other push factors - Poor compensations, remunerations, working conditions and/or career opportunities could make healthcare workers to be dissatisfied with their work and consequently relocated from their home country to other countries, most times from developing countries to developed countries. In Nigeria for instance, it is an obvious fact that several health personnel are engaged in strenuous work in the different facilities which is not commensurate with the salaries there are being paid. According to Obansa and Orimisan (2013), some even work in unsafe/insecure environments. Again among the African countries, Nigeria is one nation where majority of the health personnel sought for greener line in developed nations. Lambo (2006) reported that, over 21,000 Nigerian doctors are practicing abroad. Between April, 2001 and March, 2002, 432 Nigerian nurses legally migrated to work in Britain out of a total of about 2000 nurses that legally emigrating Africa. United Kingdom work permits were approved for 1510 nurses from Nigeria in 2003, and 850 from Ghana (UK Department of Health, 2001). The Nigerian government however sees this trend as a threat to sustainability of her healthcare system.

8) Bribery and corruption - Corruption through the embezzlement of healthcare budgets, health insurance fraud, fraudulent drug procurement or bribes extorted from healthcare consumers at delivery level have negative effects on the healthcare system both in developed and developing countries (World Bank, 2009). It also includes bribery of health professionals, regulators and public officials, stealing of medicines and medical supplies by the health personnel, overbilling for healthcare services, absence from work, and informal payments (Transparency International 2004; Vian, 2007). In Nigeria, corruption in the healthcare sector occurs among different actors which include; healthcare personnel and some government functionaries working directly or indirectly in the healthcare system. Akinbajo (2012) noted arbitrary inflation of unit price of drugs purchased by the ministry of health as part of efforts to help in the treatment of HIV aids victims. In 2008, a former minister of health, Adenike Grange, a former federal legislator, Iyabo Obasanjo and their gladiators were alleged to be involved in corruption where the sum of $\$ 300$ million was misappropriated in the ministry of health (Ogbu, 2008). Today, while the likes of Grange and Iyabo walks the streets of the country freely without being called to account, most of the poor masses who could have benefitted from the $\$ 300$ million have met with untimely death.

9) Shortage of healthcare personnel - The shortage of healthcare personnel is a global issue. According to WHO report (2006) there is a global shortage of 2.4 million doctors and nurses and midwives. Africa has an estimated 817,992 shortage (WHO report, Part 2). In Nigeria, there are 13 doctors, 92 nurses/midwives, and 64 community health workers (CHWs) working in the public sector per 100,000 population (Chankova et al, 2007). 
Sustainable Healthcare System in Nigeria: Vision, Strategies and Challenges.

Again in 2012 according to the Nursing and Midwifery Council of Nigeria (NMCN) there were 148,129 registered nurses to care for the approximated Nigeria population of above 150 million with a nurse-topopulation ratio of approximately1:1013 persons. The physician-to-population ratio was 1:2536 persons in 2007 in Nigeria (National Bureau of Statistics [NBS], 2007a) as compared with developed nation that has physicianto-population ratio of 1:410 persons in 2007 (Jhingan, 2007). Birth attended by skilled personnel in 2005 is just $35 \%$ as compared with developed nations of $95 \%$ in same 2005 (UNDP, 2007). This acute shortage is as a result of inadequate infrastructure and poor compensation packages and massive immigration of doctors, nurses and other medical professionals to developed countries in search of fulfilling and lucrative positions (Raufu, 2002; Awofeso, 2008).

\section{The Way Forward For Sustainable Healthcare Delivery System In Nigeria}

To achieve a sustainable healthcare system, the Nigerian government should:

i. Provide a system of equitable distribution of health facilities, resources (human and material) and services to those in greatest need particularly, the vulnerable populations.

ii. Ensure and implement cost-effective interventions healthcare plans that strengthen the delivery of basic health and referral services.

iii. Ensure provision and equitable distribution of agreed "essential packages of care" at all levels of the healthcare system.

iv. Establish a functional and competent monitoring and evaluation systems to track progress and changes in the health sector at all the levels of operation and periodically review their findings to improve the quality of care.

v. Engagement of all stakeholders under the leadership of the FMoH to update programs and projects to promote compatibility with the NSHDP Framework.

vi. Encourage strategic and progressive leadership in healthcare system.

vii. Provide incentives to healthcare personnel at the different levels, improve their salary structure, offer improvement career opportunities so as to retain and restrain them from seeking for a more lucrative opportunities abroad.

viii. Create an environment that is conducive for the advancement of science and research in Nigeria whilst adhering to highest ethical and scientific standards.

\section{Conclusion}

The context for health is rapidly changing and healthcare systems are deemed financially unsustainable. Nigeria health care system is poorly developed and has suffered several backdrops, especially at the Local Government Levels. Sustainability is unlikely to be achieved through these incremental changes. Instead, transformative solutions will be needed - solutions that require cooperation across industry sectors and governments, and thereby challenge the current boundaries of healthcare and established norms of operation. In other words, to meet the challenges of achieving improved health status particularly for its poorest and most vulnerable population, the health system must be strengthened; proven cost-effective interventions must be scaled up and gains in health must be sustained and expanded.

\section{References}

[1]. Adeyemo, D.O. (2005). Local Government and Health Care Delivery in Nigeria: A Case Study. J Hum Ecol. Vol.18:149-160.

[2]. Akinbajo, S. (2012). "The Massive MDG Fraud: How the Health Ministry Steals From The Sick and Dying". Available at www.premiumtimesnews/org (Accessed 29/04/2014).

[3]. Akinnaso, N. (March 25, 2014). The politics of healthcare in Nigeria. Punch (Nigerian newspaper)

[4]. Akunyili, D. (2007). Counterfeiting Medicines: "A Serious Crime Against Humanity". Available at http://www.europarl.europa.eu/comparl/dev/hearing/20070410/akunyinli.pdf (Accessed (Accessed 18/04/2014).

[5]. Awofeso N. (2008). Managing brain drain and brain waste of health workers in Nigeria. WHO (2008). Available at: http://www.who.int/bulletin/bulletin_board/82/stilwell1/en/ (Accessed 13/04/2014).

[6]. Brody, W. (2007). Remarks by Johns Hopkins University President: "Health Care '08: What's Promised/What's Possible?" 7 Sept 2007.

[7]. Central Bank of Nigeria (2008) Annual Report Abuja: Central Bank of Nigeria. Central Bank of Nigeria CBN (2005). “Annual Reports and Statement of Accounts". CBN Reports, 2000, 2001, 2002, 2003 as quoted in World Bank Country Report for Nigeria,2005.

[8]. Chankova S, Nguyen H, Chipanta D, Kombe G, Onoja A \& Ogungbemi K. (2007). Catalyzing Human Resources Mobilization: A look at the situation in Nigeria. Abt Associates Inc. May 30, 2007 Global Health Council Annual Conference, Washington DC.

[9]. Federal Ministry of Health [FMoH] (2005) Inventory of Health Facilities in Nigeria Abuja: Federal Ministry of Health.

[10]. Federal Ministry of Health (2002). National Health Survey.

[11]. Federal Ministry of Health (2001). National Health Survey.

[12]. Federal Republic of Nigeria (2004). "Health sector Reform Programme Strategic thrusts with a logical framework and a plane of action 2004-2007" (Sept).

[13]. Frenk .J. (2010). The Global Health System : Strengthening National Health Systems as the next step for Global Progress, Plos Medicine, January 2010, Vol 7 (1). Available at http://www.ncbi.nlm.nih.gov/pmc/articles/PMC2797599/ (Accessed 25/04/2014).

[14]. Health Reform Foundation of Nigeria (HERFON), (2006) “Nigeria Health Review”, Kenbim press Ltd, Ibadan. Pg10-12,130,191. 
Sustainable Healthcare System in Nigeria: Vision, Strategies and Challenges.

[15]. Jhingan, M.L. (2007). The Economics of Development and Planning. $39^{\text {th }}$ Ed. Vrinda Publications Ltd. Delhi.

[16]. Lambo, E. (2006). 'Linkages Between Poverty, Health and Sustainable Development in Africa.

[17]. Naicker, S, Plange-Rhule, J, Tutt, B.A \& Eastwood, J.B (2009). Shortage Of Healthcare Workers In Developing Countries-Africa. Ethnicity \& Disease, Vol. 19, Spring 2009. Pp $60-64$.

[18]. NBS (2007a). Social Statistics in Nigeria. National Bureau of Statistics, Abuja. Pp $5-34$.

[19]. NBS (2007b). The Nigerian Statistical Fact Sheet on Economic Development. National Bureau of Statistics, Abuja. Pp 160 - 169

[20]. NBS (2008). Annual Abstract of Statistics. National Bureau of Statistics, Abuja. Pp $74-77$.

[21]. National Demographic and Health Survey (2008). Available at http://www.nhcc.org (Accessed 25/04/2014).

[22]. National Planning Commission (2008) Draft National Development Plan Abuja: National Planning Commission.

[23]. National Primary Health Care Development Agency (2012). National Guidelines for Development of Primary Health Care System in Nigeria. $4^{\text {th }}$ Edition. FRN: Abuja.

[24]. National Strategic Health Development Plan (NSHDP) 2010 - 2015. Available at http://www.nshdp.org (Accessed 25/04/2014).

[25]. Nigeria Annual Health Sector Report (2010). Available at http://www.nahsr.org (Accessed 25/04/2014).

[26]. Nigeria Global Health Initiative Strategy 2010 - 2015 (2011). United States Government Interagency Team. 28 September 2011.

[27]. Obansa, S.A.J. \& Orimisan, A. (2013). Health Care Financing in Nigeria: Prospects and Challenges. Mediterranean Journal of Social Sciences Vol. 4 (1) January 2013. ISSN 2039-9340. Pp 221 - 236.

[28]. Ogbu, O. N. (2008). "Combating Corruption in Nigeria: A Critical Appraisal of the Laws, Institutions, and the Political Will". Annual Survey of International and Comparative Law: Vol. 14: Iss. 1, Article 6. Available at: http://digitalcommons.law.ggu.edu/annlsurvey/vol14/iss1/6. (Accessed 29/04/2014).

[29]. Raufu A. (2002). Nigerian health authorities worry over exodus of doctors and nurses. BMJ 2002; 325:65.

[30]. Reef, M. S. (2008). Nigeria: Why New Malaria Strain resists Drugs?" Daily Trust. Available at http://allafrica.com/stories/200803170779.htm (Accessed 18/04/2014).

[31]. Reproductive Health Situation in Nigeria: ENHANCE Project, (2005). Available at http://www.enhanceproject.org (Accessed 25/04/2014).

[32]. Transparency International (2004). "The National Integrity Systems; TI Country Study Report Nigeria". Available at http://www.globalcorruptionreport.org (Accessed 18/04/2014).

[33]. UK Department of Health (2001). Code of practice for NHS employers involved in the international recruitment of healthcare professionals. Available at http://www.dh.gov. uk/en/Publicationsandstatistics/Publications/ Publications Policy And Guidance/DH_4097730. (Accessed 13/05/2014).

[34]. United Nations Development Program (2007) Human Development Report. 2007/8. New York. UNDP. Pp 245 - 279. Available at http:www.unngles.org/spip.php?page=article_s\&id_article=393. (Accessed 13/05/2014).

[35]. Vian, T. (2007). "Review of corruption in the health sector" Health Policy and Planning, Vol. 23(2). Pp. 65-78.

[36]. World Economic Forum (2013). Available at http://wwwwef.org (Accessed 25/04/2014).

[37]. World Health Organization. (2007). Everybody's Business. Strengthening Health Systems to Improve Health Outcomes : WHO's framework for action.

[38]. World Health Organization (2006). The World Health Report: "Working together for health". World Health Organization. Available at http://www.who.int/whr/2006/en/ (Accessed 13/04/2014).

[39]. World Health Organization Report. Part 2: Global Health Indicators http://www.who.int/whosis/whostat/EN_WHS08_Full.pdf. (Accessed 13/04/2014).

[40]. World Health Organization (2006). Country health system fact sheet, 2006 Nigeria. Available at URL: http://www.afro.who.int/index.php?option=com_content\&view=article\&id=1047\&Itemid=1936 or http://www.afro.who.int/en/ nigeria/who-country-office-nigeria.html (Accessed 13/04/2014).

[41]. World Health Organization. (2000). World Health Report 2000 - Health systems: improving performance. Geneva, WHO. Available at http://www.who.int/whr/2000/en/index.html (accessed 25/04/2014).

[42]. Yankus, W. (2006). "Counterfeit Drugs: Coming to a Pharmacy Near You". American Council on Science and Health. Available at www.acsh.org/publications/pubid.1379/pub_detail.asp (Accessed 29/04/2014). 